\title{
Impact of sex and body mass index on cecal intubation time. Is it a myth that colonoscopy is easier to perform in obese than lean people?
}

\author{
Elżbieta Poniewierka', Robert Dudkowiak', Witold Marczyński² \\ ${ }^{1}$ Division of Dietetic, Department of Gastroenterology and Hepatology, Wroclaw Medical University, Poland \\ 2 Department of Gastroenterology, Distric Hospital in Świdnica, Poland
}

\begin{abstract}
Introduction. Colonoscopy is the gold standard for prevention and early diagnosis of colorectal cancer. Procedure quality is an important issue. Current quality indicators, such as cecal intubation rate, adenoma detection rate, and withdrawal time, are important, but cecum intubation time influences all of them. Factors that determine cecal intubation time (CIT) include body mass index (BMI), age, sex, history of abdominal surgery, quality of bowel preparation, and visceral adipose tissue. Among those who perform colonoscopy, it is believed that the procedure is easier to perform in obese people.

Aim. To determine whether cecal intubation time depends on body mass index and sex of patients undergoing colonoscopy.

Material and Methods. An analysis of the technical aspects of colonoscopy, such as the time required to intubate the cecum, with respect to BMI and sex in 100 patients.

Results. The average time taken to reach the cecum or ileum was slightly longer in obese people than in people with normal weight. Average CIT was almost one minute longer in men than women. Average CIT in obese men was slightly longer than in normal weight men. There was no difference in average CIT in obese and normal weight women. The differences were not statistically significant.

Conclusions. This study demonstrates that the claim that endoscopic examination of the lower gastrointestinal tract is easier to perform in obese people cannot be objectively confirmed.
\end{abstract}

Keywords: colonoscopy, cecal intubation time, quality in colonoscopy.

\section{Introduction}

Colonoscopy is the gold standard for the prevention and early detection of colon cancer and rectal cancer [1-6]. It is important to remember that the effectiveness of colonoscopy depends on the quality of the procedure, which is assessed using a variety of quality indicators. Historically, the most commonly applied and recognized indicators include availability of the cecum and frequency of detection of adenomas $[1,3$, 4], but these are not the only quality indicators. Others indicators include time of retraction of the apparatus [1,
$4-7]$, degree of bowel preparation for examination $[2,6$, 7], time required to reach the cecum until the retraction of the apparatus $[1,8,9]$, endoscopist experience $[2,6]$, patient tolerance to examination $[5,6]$, suitable periodicity of examinations $[4,7]$, and use of diastolic drugs and analgosedation [6].

The availability of the cecum and many of the above-mentioned quality indicators are significantly affected by the time needed to reach the cecum/ileum or cecal intubation time (CIT). CIT reflects the endoscopist's level of experience and technical difficulties 
and affects tolerance and time of the examination. Some authors argue that CIT is just as important as the time to retract the apparatus, because while entering, the apparatus detects more polyps greater than $1 \mathrm{~cm}$ than in the process of retraction (75\% vs. $25 \%$ ) [10]. Among the many factors affecting time needed to reach the cecum are body mass index (BMI), gender, age, previous abdominal surgeries, degree of bowel cleansing, amount of visceral fat, and number of pregnancies and births in women [11-16]. The available literature does not offer much in the way of evaluating the effect of patient BMI and gender on CIT and the available texts present differing results although anecdotal evidence is commonly presented. It was therefore decided to investigate the impact of patient BMI and gender.

\section{Material and Methods}

The analysis included 100 diagnostic colonoscopy examinations performed by a single experienced endoscopist during the period from November 2014 to July 2015. The analysis excluded surgical colonoscopies and those performed under analgosedation. The following parameters were evaluated: BMI, gender, and time to reach the cecum or ileum. There were 58 women and 42 men examined. The average age of women was 63.0 and for men 59.3 years. Patients were divided into groups by gender and BMI (below and above 25 $\mathrm{kg} / \mathrm{m}^{2}$ ). The group of patients with BMI below $25 \mathrm{~kg} / \mathrm{m}^{2}$ numbered 34 people.

The group of patients with a BMI greater than 25 $\mathrm{kg} / \mathrm{m}^{2}$ numbered 66 people. Among the women, $39 \mathrm{had}$ a BMl over $25 \mathrm{~kg} / \mathrm{m}^{2}$ and 19 had a BMI less than $25 \mathrm{~kg} / \mathrm{m}^{2}$. Among men, 27 had a BMl greater than $25 \mathrm{~kg} / \mathrm{m}^{2}$ and 15 had a BMI less than $25 \mathrm{~kg} / \mathrm{m}^{2}$. The research was carried out both on an outpatient basis and in a hospital. All patients were prepared using the same laxative preparation. The quality of cleansing was rated with the Lie- berman scale. The tests were commenced typically in a left-sided position and, if necessary, the position was switched to the back; additional help from an endoscopy nurse was available. All tests were performed under sedation with midazolam or pethidine. Statistical analyses included calculation of arithmetic mean and standard deviation. Comparisons between groups were performed using Student's t test. P-values $<0.05$ were considered statistically significant.

\section{Results}

Patients were divided into two main groups according to gender and BMI and four subgroups by BMI within gender groups. Group 1 consisted of patients with a BMI of less than $25 \mathrm{~kg} / \mathrm{m}^{2}$, normal body weight; group 2 - patients with a BMl greater than $25 \mathrm{~kg} / \mathrm{m}^{2}$, overweight/obese. Subgroups $1 \mathrm{~A}$ and $1 \mathrm{~B}$ were women and men of normal weight, respectively. Subgroups $2 A$ and $2 B$ were overweight/obese women and men, respectively. The average time to reach the cecum in patients with a BMI of less than $25 \mathrm{~kg} / \mathrm{m}^{2}$ was $7.88 \pm 3.6 \mathrm{~min}$ utes, and in patients with a BMI of over $25 \mathrm{~kg} / \mathrm{m}^{2}$ was $8.12 \pm 4.4$ minutes $(p=0.440)$. Average CIT, in the case of overweight/obese patients was slightly longer than the average CIT in people with normal body weight, but the demonstrated difference was not statistically significant.

In women, the average CIT was $8.33 \pm 4.2$ minutes and in men $7.47 \pm 3.9$ minutes $(p=0.766)$. The average CIT for men was shorter by less than a minute, but this difference was not statistically significant. In the subgroup of women with normal body weight, CIT was $8.3 \pm 4.2$ minutes and in the subgroup of overweight/ obese women was $8.6 \pm 4.5$ minutes $(p=0.411)$. There was no difference in the CIT in these subgroups of women. In the subgroup of men with normal weight, CIT was $7.7 \pm 4.7$ minutes and in the subgroup of overweight/obese men was $6.9 \pm 1.9$ minutes $(p=0.677)$.

Table 1. Mean time required to intubate the cecum by gender (mean \pm standard deviation)

\begin{tabular}{|c|c|c|c|}
\hline Group & Women & Men & Total \\
\hline \multicolumn{4}{|c|}{ Normal Weight $\left(\mathrm{BMI}<25 \mathrm{~kg} / \mathrm{m}^{2}\right)$} \\
\hline Number of patients & 19 & 15 & 34 \\
\hline Average time of cecum intubation (minutes) & $8,6 \pm 4,5$ & $6,9 \pm 1,9$ & $7,8 \pm 3,6$ \\
\hline \multicolumn{4}{|c|}{ Overweight/Obese $\left(\mathrm{BMI}>25 \mathrm{~kg} / \mathrm{m}^{2}\right)$} \\
\hline Number of patients & 39 & 27 & 66 \\
\hline Average time of cecum intubation (minutes) & $8,3 \pm 4,2$ & $7,7 \pm 4,7$ & $8,1 \pm 4,4$ \\
\hline \multicolumn{4}{|c|}{ All Patients } \\
\hline Number of patients & 58 & 42 & 100 \\
\hline Average time of cecum intubation (minutes) & $8,3 \pm 4,2$ & $7,4 \pm 3,9$ & $8,0 \pm 4,1$ \\
\hline
\end{tabular}

Differences between groups were tested using Student's t test 
CIT was a bit lower for overweight and obese men, but this difference was also not statistically significant. The results are presented in table form in Table 1.

Analysis of the obtained values shows that the time to reach the cecum in obese people differed slightly between groups, but the difference between groups was not statistically significant. No significant difference between obese and lean people was found with respect to $\mathrm{CIT}$.

\section{Discussion}

In order to be effective, efficient, and safe for the patient, every medical procedure must be performed carefully. In assessing the quality of colonoscopy, of key importance is the viewing by the endoscopist of the entire colon and detection of any pathological changes. Viewing the cecum is particularly important as there has recently been an increasing incidence of cancers located in the right half of the colon. Many presently recognized quality parameters, such as availability of the cecum, adenoma detection rate, and time of endoscope retraction, amongst others, influence time to reach the cecum and therefore alter the degree of difficulty of the examination and patient tolerance.

It is known that better tolerated examinations favor an increase in the number of detected adenomas [1] A few studies have analyzed the impact of various factors on colonoscopy quality. Of particular interest is the impact of patient BMI and gender on CIT.

Chung et al. analyzed 1386 patients who underwent colonoscopy and a computed tomography (CT) scan of the abdomen on the same day. They evaluated age, gender, BMI, height, diameter of the waist and hips, previous operations in the abdomen region, irritable bowels syndrome symptoms, quality of bowel cleansing, endoscopist experience, and amount of visceral fat in the abdomen as assessed by CT. The authors found that female gender, older age, lower height, lower BMI, previous operations in the abdomen region, as well as a smaller amount of body fat, were associated with longer time required to reach the cecum [12]. Park et al. assessed the factors influencing the successful intubation the cecum. The authors analyzed 2050 people who had undergone colonoscopy. A complete colonoscopy was achieved in $83.9 \%$. Failure was associated with factors such as female gender, BMI $<18.5 \mathrm{~kg} / \mathrm{m}^{2}$, poor bowel cleansing, and previous surgical procedures in the abdomen [13]. Uddin et al. found that obesity $\left(\mathrm{BMI}>30 \mathrm{~kg} / \mathrm{m}^{2}\right)$ is a factor inhibiting the execution of colonoscopy and reaching the cecum.
They compared average time to reach the cecum in two groups of obese patients depending on the position in which the examination was performed. The first group was tested laying on their stomach and the other in the traditional left-sided position. A statistically significant reduction in the time to reach the cecum was found in the first group [14]. Bernstein et al. examined factors related to the time required for intubation of the cecum. They found that the extra time needed to reach the cecum is associated with factors such as older age, female gender, lower BMI, poor bowel preparation, and a less experienced endoscopist [15]. Andreson et al. studied the effects of BMI on the effectiveness of reaching the cecum. They analyzed 2000 examinations carried out over two years in one center, dividing patients into groups according to gender and BMI. They found that a failure of examination was associated with female gender and low BMI, especially $<22 \mathrm{~kg} /$ $\mathrm{m}^{2}$ [16]. Review of the literature and finding presented here suggest that there is no conclusive evidence that high BMI is a factor that facilitates the endoscopist in the performance of an effective colonoscopy. However, in many studies BMI is mentioned as one of the factors influencing the time of examination. Such opinions were also analyzed in this study and it was found that it cannot be concluded that there is a significant association between patient BMI and/or gender and cecal intubation time during endoscopic examination of the colon.

\section{Acknowledgements}

\section{Conflict of interest statement}

The authors declare no conflict of interest.

\section{Funding sources}

There are no sources of funding to declare.

\section{References}

1. Kotowski B, Kamiński MF, Rupiński M et al. Analiza jakości kolonoskopii w Ogólnopolskim Programie Badań Przesiewowych dla Wczesnego Wykrywania Raka Jelita Grubego. Gastroenterologia Kliniczna. 2009;1(1):45-53.

2. Atia MA, Ramirez FC, Gurudu SR. Quality monitoring in colonoscopy: Time to act. World J Gastrointest Endosc. 2015 Apr 16;7(4):328-335.

3. Ennaifer R, Elleuch N, Sabbagh $S$ et al. Quality indicators for colonoscopy in a Tunisian endoscopy unit. Tunis Med. 2015 Mar;93(3):138-141.

4. Allen JI. Quality measures for colonoscopy: where should we be in. 2015. Curr Gastroenterol Rep. 2015 Mar;17(3):10.

5. Anderson JC, Butterly LF. Colonoscopy: quality indicators. Clin Transl Gastroenterol. 2015 Feb 26;6:e77. 
6. Lee TJ, Rees CJ, Blanks RG et al. Colonoscopic factors associated with adenoma detection in a national colorectal cancer screening program. Endoscopy. 2014 Mar;46(3):203-211.

7. Brunner KT, Calderwood AH. Quality in Colonoscopy. Curr Gastroenterol Rep. 2015 Oct;17(10):401.

8. Choung BS, Kim SH, Yoo KB et al. Should Assessment of Quality Indicator of Colonoscopy Be Varied Depending on the Colonoscopic Technique Level? Dig Dis Sci. 2015 Nov 17 [epub ahead of print].

9. Benson ME, Reichelderfel M, Said A et al. Variation in colonoscopic technique and adenoma detection rates at anacademic gastroenterology unit. Di Dis Sci. 2010 Jan;55(1):166-171.

10. Morini S, Hassan C, Zullo A. Detection of colonic polyps according to insertion/withdrawal phases of colonoscopy. Int J Colorectal Dis. 2009 May:24(5):527-530.

11. Park HJ, Hong JH, Kim HS et al. Preictive factors affecting cecal intubaction failure in colonoscopy trainees. BMC Med Educ. 2013 Jan 19;13:5.

12. Chung GE, Lim SH, Yang SY et al. Factors that determine prolonged cecal intubation time during colonoscopy: impact of visceral adipose tissue. Scand J Gastroenterrol. 2014;49:1261-1267.

13. Park HJ, Hong JH, Kim HS et al. Predictive factors affecting cecal intubation failure in colonoscopy trainees. BMC Med Educ. 2013;13:5.
14. Uddin FS, Iqbal R, Harford WV et al. Prone positioning of obese patients for coonoscopy results in sghortened cecal intubation time: a randomized trial. Dig Dis Sci. 2013;58(3):782-787.

15. Bernstein $\mathrm{C}$, Thorn $\mathrm{M}$, Monsees $\mathrm{K}$ et al. A prospective study of factors that determine cecal intubation time at colonoscopy. Gastroinetest Endosc. 2005;61(1):72-75.

16. Anderson JC, Gonzales JD, Messina CR, et. Factors that predict incomplete colonoscopy: thinner is not always better. Am J Gastroenterol. 2000;95(10):2784-2787.

Acceptance for editing: 2016-12-10 Acceptance for publication: 2016-12-22

Correspondence address: Robert Dudkowiak Division of Dietetics Department of Gastroenterology and Hepatology Wroclaw Medical University, Poland email: robindud@op.pl 